\title{
David Oliver: Top healthcare words of 2018
}

\author{
David Oliver consultant in geriatrics and acute general medicine
}

Berkshire

The Collins English Dictionary's top 10 words of $2018^{1}$ included "plogging" (picking up litter while jogging), "VAR" (video assistant referee), and "floss" (a new dance craze). So, as The $B M J$ heads to the New Year, here's my personal list of the top words of 2018 for UK health services. I've doubtless missed some, so please do post rapid responses or tweet your own suggestions.

\section{Plan}

It's been good to see, for the first time in the NHS's history, a draft workforce plan (technically, a "strategy")—from Health Education England. ${ }^{2}$ It has its imperfections, but at least it's a plan. And we're eagerly expecting the launch of NHS England's 10 year plan for the health service. ${ }^{3}$ Again, not everyone will be happy with its details, but a shift towards medium term plans beats short term, politically driven cycles. It's a start.

\section{Workforce}

To my mind, ${ }^{4}$ and that of major healthcare think tanks, ${ }^{5}$ the problems facing the healthcare workforce are the single biggest threat to sustainability of health services. One in 11 medical posts is unfilled, as is one in nine nursing posts. ${ }^{6}$ Services face attrition from training posts among junior doctors and crises in primary care, community care, and busy acute specialties. In a survey NHS senior managers recognised workforce gaps as their biggest challenge. ${ }^{7}$ And NHS Providers ${ }^{8}$ has set out some urgent solutions. My campaigning slogan for 2019 should be: "It's not a plan without a workforce plan."

\section{Person centred}

Person centred care has remained a prominent theme for the NHS in 2018. "Multimorbidity" and "frailty" feature prominently in discussions as healthcare becomes increasingly about people who have many problems at the same time rather than just one disease. Yet the experiences of patients and families show that delivering person centred care is still far from the norm. ${ }^{9}$ Despite a culture in social care that has long valued personalisation, severe cuts to social care funding and provision mean that people with needs-and, crucially, their carers-are increasingly denied support. ${ }^{10-12}$ Person centred care is a key plan of NHS England's 10 year plan, and a social care green paper is in preparation. I'm hoping that they contain some good news.

My campaigning slogan for 2019 should be: 'It's not a plan without a workforce plan'

\section{Al}

This year Matt Hancock, England's health secretary, threw his enthusiasm behind the push towards digital technology and artificial intelligence (AI).$^{13}$ AI featured in Hancock's recent vision for prevention, ${ }^{14}$ as well as in the Department of Health and Social Care's digital vision for healthcare and NHS England's digital strategy. ${ }^{15}{ }^{16}$ I'd say that it's too early to predict how transformative technology will be, whether it's AI, precision medicine, electronic health records, or technology enabled care. And independent empirical evidence about its adoption and impact is way behind the euphoric speculation. ${ }^{17}$

\section{Winter}

"Winter" and "winter pressures" continue to star in discussions of demands on urgent care systems, although "year round" is appearing more often than before as we realise that winter pressures aren't just for Christmas. And "waits" or "delays" go hand in hand with this: in emergency departments, in elective operations or procedures, or when leaving hospital and requiring community services.

We have national good practice guidance, exhortations, and performance management support from national NHS leadership. ${ }^{18}$ But underlying structural problems around low hospital bed capacity, under-resourced primary and community services, rising demand, and public attraction to acute care solutions will take years to solve. Any care systems that manage even to slow the growth in admission or attendance rates or in delayed transfers out of hospital are doing well. 


\section{And the number one is ... .}

For Collins the top word of the year was "single use." I was tempted to pick "record injection" —as in, of money-often used by ministers to describe the additional $£ 20.5$ bn promised for the NHS through to 2023-24. This sum is welcome, but independent expert commentators make clear that it's barely enough to sustain current performance levels, let alone bring transformation. ${ }^{1920}$

But there can be only one winner and, sadly, it would also have been top in 2016 and 2017: "Brexit." Until that issue is resolved the entire machinery of government will be preoccupied by it—and, once it's done, its impact on the NHS and biomedical research will be profound. As for a Brexit “plan," we still don't have one.

Competing interests: See www.bmj.com/about-bmj/freelance-contributors/davidoliver.

Provenance and peer review: Commissioned; not externally peer reviewed.

1 Collins Dictionary. Word of the year. 2018. https://www.collinsdictionary.com/woty.

2 Health Education England. Facing the facts, shaping the future. Dec 2017. https://www. hee.nhs.uk/our-work/workforce-strategy.

3 Ham C, Murray R. The NHS 10-year plan: how should the extra funding be spent?King's Fund. 12 July 2018. https://www.kingsfund.org.uk/publications/nhs-10-year-plan.

4 Oliver D. David Oliver: NHS workforce policy is not joined-up government. BMJ 2018;363:k4417. https://www.bmj.com/content/363/bmj.k4417.

5 King's Fund. The health care workforce in England: make or break? 15 Nov 2018. https: //www.kingsfund.org.uk/publications/health-care-workforce-england.

6 NHS Digital. NHS workforce statistics. https://digital.nhs.uk/data-and-information/ publications/statistical/nhs-workforce-statistics.
7 NHS Providers. There for us: a better future for the NHS workforce. Nov 2017. https:// nhsproviders.org/a-better-future-for-the-nhs-workforce.

8 NHS Providers. Priorities for the NHS workforce. https://nhsproviders.org/topics/workforce/ priorities-for-the-nhs-workforce.

9 National Voices. A narrative for person-centred coordinated care. May 2013. https://www. nationalvoices.org.uk/publications/our-publications/narrative-person-centred-coordinatedcare.

10 Redding D, Hutchinson S. Person-centred care in 2017: evidence from service usersNational Voices. Sept 2017. https://www.nationalvoices.org.uk/publications/ourpublications/person-centred-care-2017.

11 Carers UK. State of caring 2018. 10 July 2018. https://www.carersuk.org/for-professionals/ policy/policy-library/state-of-caring-2018-2.

12 King's Fund. Social care for older people: home truths. 15 Sept 2016. https://www. kingsfund.org.uk/publications/social-care-older-people.

13 Department of Health and Social CareHancock M. My vision for a more tech-driven NHS 6 Sept 2018. https://www.gov.uk/government/speeches/my-vision-for-a-more-tech-drivennhs.

14 Oliver D. David Oliver: Is Matt Hancock really prioritising prevention over cure? BMJ 2018;363:k4712. https://www.bmj.com/content/363/bmj.k4712.

15 NHS England. Harnessing technology and innovation. https://www.england.nhs.uk/fiveyear-forward-view/next-steps-on-the-nhs-five-year-forward-view/harnessing-technologyand-innovation/.

16 Department of Health and Social Care. The future of healthcare: our vision for digital, data and technology in health and care. 17 Oct 2018. https://www.gov.uk/government/ publications/the-future-of-healthcare-our-vision-for-digital-data-and-technology-in-healthand-care.

17 Health Innovation Network South London. NHS England TECS evidence base review: findings and recommendations. 28 April 2017. https://healthinnovationnetwork.com/wpcontent/uploads/2017/08/NHS-TECS-Evidence-Base-Review-Findings-andrecommendations.pdf.

18 NHS Improvement. Managing increased demand from winter illness. 29 June 2018. https: //improvement.nhs.uk/resources/managing-increased-demand-winter-illness/.

19 NHS Confederation. Revealed: the reality behind the 2019-24 NHS funding settlement 12 Oct 2018. https://www.nhsconfed.org/news/2018/10/revealed-reality-of-the-nhs-fundingsettlement.

20 Gainsbury S. NHS funding boost: the need to manage expectations Nuffield Trust. 26 Oct 2018. https://www.nuffieldtrust.org.uk/news-item/nhs-funding-boost-the-need-to-manageexpectations.

Published by the BMJ Publishing Group Limited. For permission to use (where not already granted under a licence) please go to http://group.bmj.com/group/rights-licensing/ permissions 